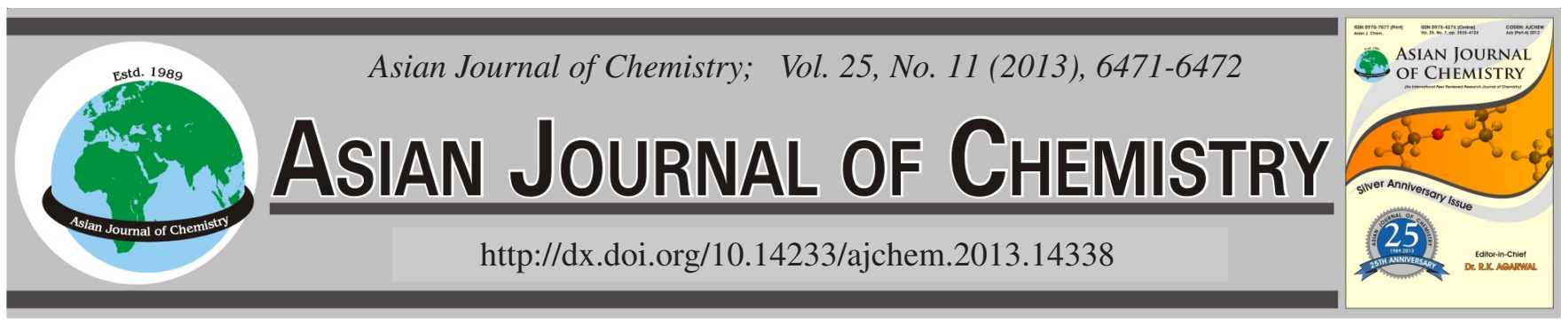

NOTE

\title{
Organoclay as a Highly Efficient Catalyst for Three-Component One-Pot Biginelli Synthesis of Octahydroquinazolinone Derivatives
}

\author{
SOHEIL SAYYAHI
}

Department of Chemistry, Mahshahr Branch, Islamic Azad University, Mahshahr 63519, Iran

Corresponding author: E-mail: sayyahi.soheil@gmail.com

(Received: 19 July 2012;

Accepted: 14 May 2013)

AJC-13502

In this study, the synthesis of octahydroquinazolinone derivatives via three-component Biginelli reaction is reported. The organoclaycatalyzed process proved to be simple, efficient and environmentally friendly.

Key Words: Organoclay, Biginelli three-component reaction, Heterogeneous catalyst.

Organic synthesis performed through multicomponent reactions (MCRs) is an attractive area of research in organic and medicine chemistry ${ }^{1}$. Although most of the established multicomponent reactions do not require a catalyst, the search for new multicomponent reaction products has resulted in an intensified effort to find catalysts and new catalyzed multicomponent reactions. However, it was seen that most of the work has been performed using homogeneous catalysts and the number of catalytic studies with solid catalysts is still limited ${ }^{2}$.

Clays and organically modified form clays are versatile materials that catalyze various types of chemical reaction ${ }^{3}$. The nature of the microenvironment between the aluminosilicate sheets of clay regulates the topology of the intercalated molecules and affects possible supramolecular rearrangements or reactions that are usually difficult to control in solution ${ }^{4}$.

Herein and in continuation to our effort to introduce new application of heterogeneous catalyst ${ }^{5}$ and reagent ${ }^{6}$, we would like to report an efficient route for the synthesis of octahydroquinazolinone derivatives using organoclay as catalyst in water. Due to biological and pharmacological properties ${ }^{7}$, several methods have been developed for the preparation of octahydroquinazolinone derivatives ${ }^{8}$. However, many of these procedures suffer from disadvantages such as harsh reaction conditions, prolonged time period, poor yields and use of hazardous and expensive catalysts ${ }^{9}$. Then, the development of a clean, high-yielding and environmentally friendly approach is still desirable.

Chemicals were purchased from Aldrich and Merck Chemical companies and used without further purification. NMR spectra were recorded in $\mathrm{CDCl}_{3}$ on a Bruker Advance
DPX $400 \mathrm{MHz}$ instrument spectrometer using TMS as an internal standard. IR spectra were recorded on a BOMEM MB-Series 1998 FT-IR spectrometer. The purity of the products and reaction monitoring were followed by thin layer chromatography on silica gel polygram SILG/UV $F_{254}$ plates. Natural bentonite was procured from Khorasan Mines, Iran (XRF analysis: $\mathrm{SiO}_{2}=51.2 \%, \mathrm{Al}_{2} \mathrm{O}_{3}=10.7 \%, \mathrm{CaO}=12.8 \%$ ) and was ground, sieved (200-mesh), washed with water and dried in $100{ }^{\circ} \mathrm{C}$ for $2 \mathrm{~h}$ before using. Organoclay was synthesized according to the reported procedure ${ }^{10}$ using cetyltrimethylammonium bromide as surfactant to widen spacing between platelets (Scheme-I).

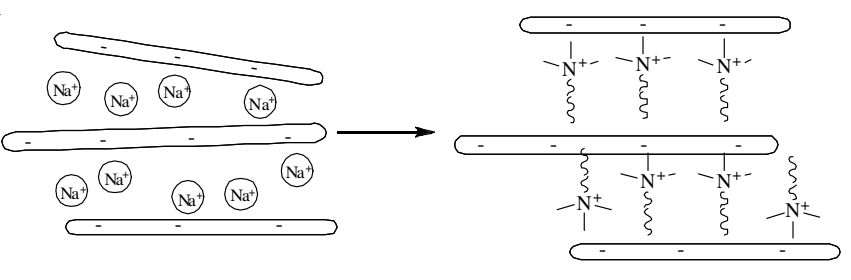

Scheme-I: Preparaion of organoclay

A solution of dimedone ( $2 \mathrm{mmol})$, aldehyde $(2 \mathrm{mmol})$, urea/thiourea ( $3 \mathrm{mmol})$ and organoclay $(0.5 \mathrm{~g})$ in water $(5 \mathrm{~mL})$ was heated under reflux condition for time shown in Table-1. The progress of the reactions was monitored by TLC. The catalyst was filtered and product was extracted with hot ethanol and then the product recrystallized with ethanol to give the corresponding compound. All products are known and were characterized by comparison of their physical data, IR and ${ }^{1} \mathrm{H}$ NMR spectra with those of authentic samples. 


\begin{tabular}{cllcc}
\hline & TABLE-1 \\
& & & \\
\end{tabular}

${ }^{a}$ Products were identified by comparison of their physical and spectral data with those of authentic samples ${ }^{7,8 a}$. bIsolated yields.

Modification of clay by ion exchange with cetyltrimethylammonium bromide makes hydrophilicity decrease and enhances the organophilicity in the interlayers of clay ${ }^{11}$. Therefore, organoclay may play an important role in catalyzing the Biginelli reactions and synthesis of octahydroquinazolinone.

Reaction condition was optimized by varying amount of catalyst loading and temperature. The best result was obtained when $0.5 \mathrm{~g}$ of organoclay as heterogeneous catalyst treated under reflux condition with 2:2:3 mmol dimedon, aldehyde and urea or thiourea in water. The potential scope of this method was evident when a variety of aromatic aldehydes bearing both electrondonating and electron-withdraw groups in the ortho, meta and para-positions underwent the reaction. As shown by the results in Table-1, all the examined substrates could furnish the desired products in appropriate time and high yields.

The possibility of recycling organoclay was checked. The catalyst was used for several times after recovering by simple filtration and washing with ethanol, without appreciable loss in catalytic activity.

\section{ACKNOWLEDGEMENTS}

The financial support of this work by Mahshahr Branch, Islamic Azad University is greatly appreciated.

\section{REFERENCES}

1. (a) J. Zhu and H. Bienayme, Multicomponent Reactions, Wiley-VCH Verlag GmbH \& Co. KGaA, Weinheim (2005); (b) A. Dömling and Y. Huang, Synthesis, 2859 (2010).

2. M.J. Climent, A. Corma and S. Iborra, RSC Adv., 2, 16 (2012).

3. (a) G. Nagendrappa, Appl. Clay Sci., 53, 106 (2011); (b) V. Singh, R. Ratti and S. Kaur, J. Mol. Catal. A, 334, 13 (2011).

4. E. Serefoglou, K. Litina, D. Gournis, E. Kalogeris, A.A. Tzialla, I.V. Pavlidis, C. Stamatis, E. Maccallini, M. Lubomska and P. Rudolf, Chem. Mater., 20, 4106 (2008).

5. (a) A.R. Kiasat and S. Sayyahi, Catal. Commun., 11, 484 (2010); (b) S. Sayyahi and Saghanezhad, J. Chin. Chem. Lett., 22, 300 (2011); (c) M. Gorjizadeh and S. Sayyahi, Chin. Chem. Lett., 22, 659 (2011).

6. A.R. Kiasat and S. Sayyahi, Mol. Divers., 14, 155 (2010).

7. Z. Hassani, M.R. Islami and M. Kalantari, Bioorg. Med. Chem. Lett., 16, 4479 (2006).

8. (a) S. Kantevari, R. Bantu and L. Nagarapu, Arkivoc, 136 (2006); (b) H. Lin, Q. Zhao, B. Xu and X. Wang, J. Mol. Catal. A, 268, 221 (2007); (c) M. Yarim, S. Sarac, F.S. Kilic and K. Erol, IL Farmaco, 58, 17 (2003); (d) S. Samantaray and B.G. Mishra, J. Mol. Catal. A, 339, 92 (2011).

9. K.S. Niralwad, B.B. Shingate and M.S. Shingare, Tetrahedron Lett., 51, 3616 (2010).

10. S. Sonawane, P. Chaudhari, S. Ghodke, S. Ambade, S. Gulig, A. Mirikar and A. Bane, Ultrason. Sonochem., 15, 1033 (2008).

11. J. Zhu, L. Zhu, R. Zhu and B. Chen, Clays Clay Miner., 56, 144 (2008). 